\title{
Interdigitated electrode for degradation assessment of palm olein during batch deep fat frying
}

\begin{abstract}
ABSTRCT
Repeated use of frying oil has been proven hazardous due to the degradation process that changes the quality of the oil. In this study, an interdigitated electrode (IDE) sensor was designed to evaluate palm olein degradation during deep fat frying at several frying intervals by measuring the changes in the oil's electrical properties. The frying experiment was carried out in batches. In total, 150 batches (150 g batch-1) of French fries were fried over five days. Oil samples were collected $(150 \mathrm{~mL})$ after every five frying cycles. The impedance values were measured at $35^{\circ} \mathrm{C}$ and $45^{\circ} \mathrm{C}$ using the IDE sensor connected to aninductance (L), capacitance (C), and resistance (R) LCR meter with five frequency levels $(100 \mathrm{~Hz}, 1 \mathrm{kHz}, 10 \mathrm{kHz}, 20 \mathrm{kHz}$, and $100 \mathrm{kHz}$ ). The total polar compounds (TPC) of each oil sample were measured with a Testo 270 frying oil tester, while the viscosity was measured with a viscometer. The impedance values were found to be significantly different at $35^{\circ} \mathrm{C}$ and $45^{\circ} \mathrm{C}$ as well as at different frequency levels $(\mathrm{p}<0.0001)$. For individual frequency analysis, the regression equation obtained the best results at $35^{\circ} \mathrm{C}$ (with RMSE of $1.21 \%$ ) and $1.33 \mathrm{mPa}$.s for TPC and viscosity, respectively. The results indicated that the designed IDE sensor has good potential as a simple and inexpensive method for monitoring palm olein degradation during deep fat frying.
\end{abstract}

Keyword: IDE sensor; Impedance values; Frying oil quality; Total polar compounds. 